\title{
Estimation of Tropospheric Scintillations for Indian Climatic Conditions at Ka-Band Frequencies
}

\author{
R.Prabhakar, T.Venkata Ramana
}

\begin{abstract}
To estimate the scintillations effects in troposphere for the Indian climate. Here the scintillations are the one of the most important prop-agation impairment at high frequencies $(>10 G \mathrm{Gz})$ and low elevation angles $(<109$ in the satellite communication systems particularly in adaptive link control systems design. India's climate is tropical climate and vary with respect seasonally.

Up to below $4 \mathrm{~km}$ range atmosphere is called tropical region. Scintillations defined by received signal passing through this tropical climate which has turbulent mixed up with rapid signal fluctuations because due to the solar radiation earth surface heated up and small scale variations occurred in refractive index of the medium[1].
\end{abstract}

Keywordsy - Temperature, Pressure, Humidity, Scintillations.Ka band frequency, elevation angle.

\section{INTRODUCTION}

Due to the heat energy from sun incident on earth's surface warms-up, molecules are excited and at the boundary turbulent layer created. When the received are passing through this turbulence layer and mixed up and small scale variations occurred in refractive index of troposphere, due to rapid fluctuations in amplitude and angle of the received ka band frequency signals when propagating along path. Scintillations are occurred due to convective heating and gradients produces turbulences and apparent scintillations due to variations in rain drop distribution[1].

$\mathrm{Ka}$ band future satellite communication systems using ISRO. By reduced availability of spectrum and reduced interference leads in the quality of service improvement. For that available some Statistical models which are used in practice. In the ka band frequency statistical model performance to be tested for most accurate one should be recommended for the use. One of ISRO centre of SAC proposed propagation experiment at $\mathrm{Ka}$ band over Indian Climate. The satellite used. with linear polarization. measurements equipments Earth station, microwave radars, metrological sensors, radio meters are installed for the measurements to analyse and process data. Two methods used for statistical prediction .An outcome of data collection and analysis would be recommend a technique for prediction of scintillations in ka band over Indian areas and to estimate scintillations in tropical climate at $30 / 20 \mathrm{GHz}$ region. India has unique future that it has a tropical climate with different metrological conditions, various geographical

Revised Manuscript Received on August 14, 2019.

R.Prabhakar, Research Scholar, Gitam University, Visakhapatnam, A.P, India

Dr.T.Venkata Ramana, Asoc.Prof., ECE, Gitam University, Visakhapatnam, A.P, India, regions and rainfall rate areas and different elevation angles for the satellites.

Satellite communication: Geo satellites at Ka band links from sub satellite point in latitude or longitude beyond $81.34^{\circ}$ not visible.

An elevation angle decreases at the visible portion from sub satellite zenith point to zero, evolution path of circular fringe to satellite from sub satellite point of longitude at latitude from 0 to $81.34^{\circ}$ and longitude $10^{\circ}$ of earth station . At $70^{\circ}$ latitude the maximum elevation angle $11.5^{\circ}$ and at $80^{\circ}$ latitude decreased to $1.33^{\circ}$. Ray bending and ducting due to Scintillations and large scale refractive index produces fades of $20 \mathrm{dBs}$. The minimum elevation angle of $5^{\circ}$ uses commercial systems[6].

\section{GSAT 4}

Metrological data collected from different sites in India at $\mathrm{Ka}$ band. The different attenuation characteristics are presented for various locations at $\mathrm{Ka}$ band for common interface and common design of system. Metrological equipments are identical in all the sites. Equipments: Ka band receiver(beacon), distrometer, radiometers, mw rain radar, tipping bucket rain gauge, data loggers and automatic weather stations[9].

Table1:GSAT 4 Specifications at Ka Band

\begin{tabular}{|r|c|c|c|}
\hline $\begin{array}{r}\text { Carrier } \\
\text { frequency }\end{array}$ & $\mathrm{GHz}$ & 20.2 & 30.5 \\
\hline polarization & - & Linear V\&H & Linear V\&H \\
\hline isolation & $\mathrm{dB}$ & 30 & 30 \\
\hline EIRP & $\mathrm{dBW}$ & 24 & 24 \\
\hline & & +-7 & +-7 \\
& & +-1 & +-1 \\
\hline Stability of & $\mathrm{ppm}$ & -55 & -55 \\
frequency & -60 & -60 \\
\hline
\end{tabular}

\section{Earth station}

Received power will be measured by earth station from satellite transmitter at $30.5 \mathrm{GHz}$ and $20.2 \mathrm{GHz}$, antenna diameter of $120 \mathrm{~cm}$, down converted to $20 \mathrm{MHz}$ and $10 \mathrm{MHz}$ respectively, bandwidth of $300 \mathrm{KHz}$ dual stage frequency convertion.to produce differential in phase and quadreture signals used for find the beacon signal amplitude and phase of satellite using fast Fourier transform. Receiver allowed

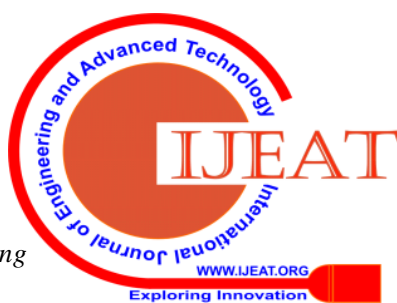




\section{ESTIMATION OF TROPOSPHERIC SCINTILLATIONS FOR INDIAN CLIMATIC CONDITIONS AT KA- BAND FREQUENCIES}

$25 \mathrm{~dB}$ and an accuracy of $0.5 \mathrm{~dB}$ sampling range of data measure between 5 and 20MHz.Dual polarization and dual frequency will be measured at a rate of $20 \mathrm{~Hz}$ by earth station. Two RF blocks used to down convert horizontal and vertical signals.

Link budget[9]

Table2:Llink budget

\begin{tabular}{|l|l|l|}
\hline Parameters & $30.5 \mathrm{GHz}$ & $20.2 \mathrm{GHz}$ \\
\hline Satellite EIRP & $24 \mathrm{dBW}$ & $24 \mathrm{dBW}$ \\
\hline Total clear sky losses & $210 \mathrm{~dB}$ & $213 \mathrm{~dB}$ \\
\hline $\begin{array}{l}\text { Power at antenna } \\
\text { feed }\end{array}$ & $-191 \mathrm{~dB}$ & $-186 \mathrm{~dB}$ \\
\hline Antenna gain & $47 \mathrm{dBi}$ & $45 \mathrm{dBi}$ \\
\hline $\begin{array}{l}\text { Received power at } \\
\text { clear sky }\end{array}$ & $-111 \mathrm{dBm}$ & $-110 \mathrm{dBm}$ \\
\hline $\begin{array}{l}\text { Threshold signal } \\
\text { power }\end{array}$ & $-147 \mathrm{dBi}$ & $-147 \mathrm{dBi}$ \\
\hline Figure of merit G/T & $18 \mathrm{DBK}$ & $16 \mathrm{DBK}{ }^{-1}$ \\
\hline RESOLUTION BW & $31 \mathrm{~Hz}$ & $31 \mathrm{~Hz}$ \\
\hline Received SNR & $42 \mathrm{~dB}$ & $43 \mathrm{~dB}$ \\
\hline Threshold SNR & $11 \mathrm{~dB}$ & $11 \mathrm{~dB}$ \\
\hline Max Dynamic Range & $32 \mathrm{~dB}$ & $33 \mathrm{~dB}$ \\
\hline
\end{tabular}

\section{RADIO REFRACTIVE INDEX}

When signal receiver from the satellite which is passing through the boundary turbulent layer which is created by solar radiation heating up the surface of the earth which is caused rapid signal fluctuations occurred, caused small scale variations occurred in signal amplitude and phase angle[3] .

Refractive index in terms of radio refractivity is given by

$$
\mathrm{n}=1+\mathrm{N} \times 10^{\wedge}-6
$$

This signal crossing the turbulent mixed up with humidity, temparture and water vapour pressure. Then radio refractivity $\mathrm{N}$ is

$$
\mathrm{N}=(\mathrm{n}-1) \times 10^{\wedge} 6(\mathrm{ppm})
$$

The total refractivity contains clear dry, Ndry and wet term, Nwet

where

$$
\begin{aligned}
& \text { Nwet }=373 \mathrm{e} / \mathrm{T}^{\wedge} 2 \mathrm{ppm} \\
& \text { Ndry }=77.6 \mathrm{P} / \mathrm{T} \text { ppm }
\end{aligned}
$$

Total refractivity is given by

$$
\mathrm{N}=(4810 \mathrm{e} / \mathrm{T}+\mathrm{P}) 77.6 / \mathrm{T}
$$

Units ppm-parts per million,

$\mathrm{T}$ is Temparature in Kelvin,

P-pressure in mbar

e-water vapour pressure.

\section{ESTIMATION OF SCINTILLATIONS}

Scintillations estimated by analysed four years raw data which was collected from NRSC(National remote sensing Centre, Hyderabad and Wyomining University. Here wet term radio refractivity, Nwet considered in wet condition.

\begin{tabular}{|c|c|c|c|c|c|c|}
\hline Long Name & Month & height & Pressure & Temp & Relative $\mathrm{H}$ & Nwet \\
\hline Units & & $\mathrm{m}$ & $\mathrm{hPa}$ & c & $\%$ & $\mathrm{ppm}$ \\
\hline \multicolumn{7}{|l|}{ Comments } \\
\hline 1 & jan & 1002.96225 & 901.876 & 19.47915 & 70.981 & 52.27013 \\
\hline 2 & feb & 988.68825 & 901.63675 & 21.8065 & 65.63525 & 54.7431 \\
\hline 3 & mar & 990.208 & 901.015 & 24.0856 & 53.6172 & 59.52092 \\
\hline 4 & aprl & 999.354 & 899.3 & 26.10225 & 52.593 & 62.4339 \\
\hline 5 & may & 995.20175 & 897.366 & 27.9005 & 51.27325 & 72.82523 \\
\hline 6 & jun & 995.80325 & 894.627 & 27.5535 & 57.651 & 96.1827 \\
\hline 7 & jul & 996.53375 & 895.373 & 24.2575 & 55.9955 & 94.97777 \\
\hline 8 & aug & 1003.37475 & 894.9355 & 23.23262 & 55.73325 & 95.69813 \\
\hline 9 & sep & 1003.06775 & 895.9125 & 22.80225 & 55.93225 & 93.94747 \\
\hline 10 & oct & 994.3035 & 900.4395 & 22.38865 & 56.194 & 78.87975 \\
\hline 11 & nov & 981.03375 & 903.622 & 19.77875 & 57.6615 & 56.04543 \\
\hline 12 & dec & 1007.0545 & 898.9585 & 19.59375 & $58 . .896$ & 64.06697 \\
\hline
\end{tabular}
relative humidity and temperature averaged four years2014 to2018[4].
Table3:estimated radio refractivity wrt metreological parameters.

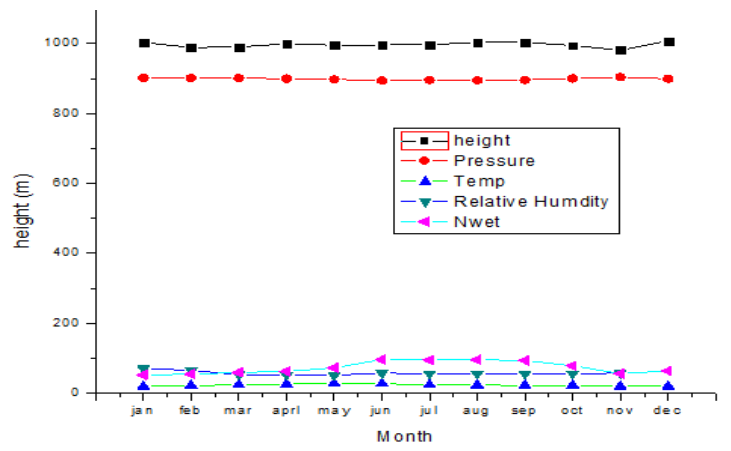

Fig.1.graph for metreological parameters

Scintillation Intensity or Standard Deviation [2]

$\operatorname{As}(\mathrm{p})=\mathrm{A}(\mathrm{p}) . \sigma, \quad \sigma=\left[\sigma \mathrm{ref} . \mathrm{f}^{\wedge} 7 / 6 . \mathrm{g}(\mathrm{x})\right] /(\sin \theta)^{\wedge} .55 \quad$ and $A(p)=A e(p)$ for enhancement due to scintillations in signals and $A(p)=A f(p)$ for faded signal due scintillations in signals for signal enhancement model

$$
\operatorname{Ae}(\mathrm{p})=-
$$

$.01711(\log p)^{\wedge} 3+0.61643(\log p)^{\wedge} 2+1.00243(\log p)+4.94481$

signal fade model

$$
\begin{gathered}
\operatorname{Af}(p)=-0.02953(\log p)^{\wedge} 3+0.37146(\log p)^{\wedge} 2- \\
0.3962(\log p)+2.75758
\end{gathered}
$$

\begin{tabular}{|c|c|c|c|}
\hline & $A(X)$ & $\mathrm{C} 1(\mathrm{r})$ & $B(Y)$ \\
\hline Long Name & month & Nwet & scintillation \\
\hline Units & hyd & ppm & $d B$ \\
\hline \multicolumn{4}{|l|}{ Comments } \\
\hline 1 & jan & 52.15905 & 0.13423 \\
\hline$\frac{2}{3}$ & feb & 54.52868 & 0.13797 \\
\hline 3 & mar & 59.11594 & 0.14488 \\
\hline 4 & apr & 61.99383 & 0.14925 \\
\hline 5 & may & 77.562 & 0.1729 \\
\hline 6 & jun & 88.897 & 0.1902 \\
\hline 7 & jul & 94.6497 & 0.199 \\
\hline 8 & aug & 95.36848 & 0.2 \\
\hline 9 & sep & 93.61858 & 0.1975 \\
\hline 10 & oct & 78.50375 & 0.17445 \\
\hline 11 & nov & 55.87455 & 0.1399 \\
\hline 12 & dec & 63.72472 & 0.1519 \\
\hline
\end{tabular}

Where $\mathrm{p}$ is time percentage factor, range from $0.001<=\mathrm{p}<=50$ where ref is the reference threshold standard level.

\section{RESULTS}

Table4:monthly averaged radio refractivity and scintillations 


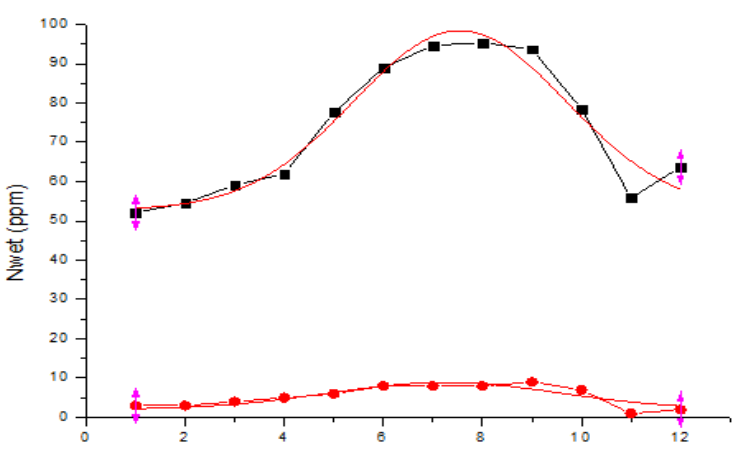

Fig2.Gaussian fitted graph for measured data

Table5:Gaussian fitted values

\begin{tabular}{|c|c|c|c|}
\hline & & Value & Standard Error \\
\hline & yo & 52.82704 & 3.5813 \\
\hline & $x c$ & 7.54418 & 0.15762 \\
\hline & w & 4.28011 & 0.53013 \\
\hline \multirow[t]{4}{*}{ Nwet } & A & 244.55823 & 42.07699 \\
\hline & sigma & 2.14005 & \\
\hline & FWHM & 5.03944 & \\
\hline & Height & 45.58979 & \\
\hline \multirow{7}{*}{ sigma } & yo & 2.02314 & 1.47952 \\
\hline & $x c$ & 7.23954 & 0.35322 \\
\hline & w & 4.69778 & 1.42282 \\
\hline & A & 40.28371 & 18.23857 \\
\hline & sigma & 2.34889 & \\
\hline & FWHM & 5.53122 & \\
\hline & Height & 6.8419 & \\
\hline
\end{tabular}

Table6: Polynomial fitted values to Nwet and Standard deviation

\begin{tabular}{|l|l|r|r|}
\hline Model & Polynomial & & \\
\hline Adj. R-Square & 0.76763 & \multicolumn{1}{|c|}{0.75629} & \\
\hline & & Value & Standard Error \\
\hline Nwet & Intercept & 46.5358 & 13.38165 \\
\hline Nwet & B1 & 0.97153 & 8.55693 \\
\hline Nwet & B2 & 1.82498 & 1.49875 \\
\hline Nwet & B3 & -0.15524 & 0.076 \\
\hline sigma & Intercept & 2.75758 & 2.18723 \\
\hline sigma & B1 & -0.39621 & 1.39863 \\
\hline sigma & B2 & 0.37146 & 0.24497 \\
\hline sigma & B3 & -0.02953 & 0.01242 \\
\hline
\end{tabular}

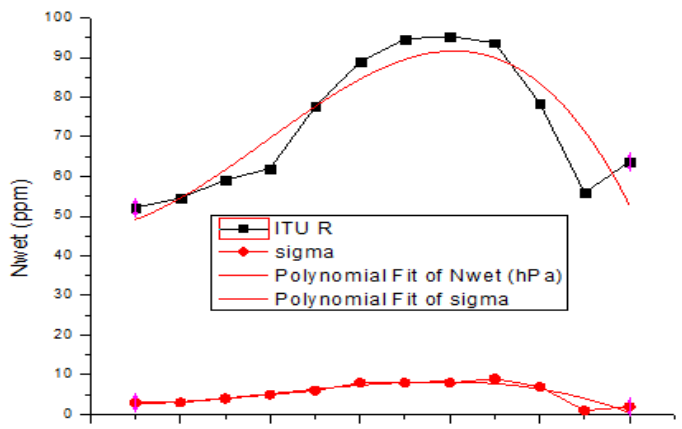

Fig.3.Polynoimial fitted curve

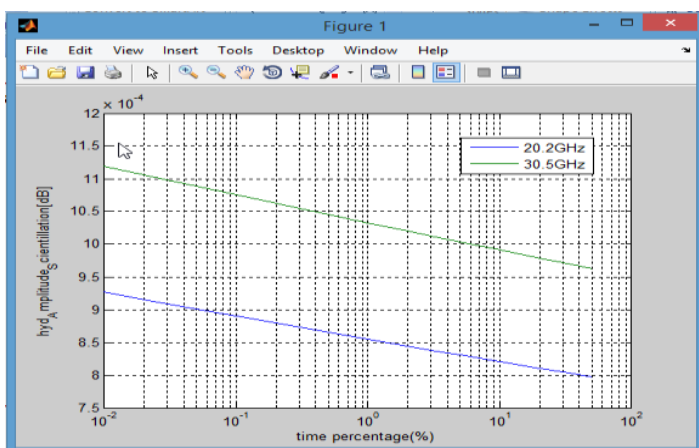

Fig4. Scintillation Intensity for $20.2 \mathrm{GHz}$ and $30.5 \mathrm{GHz}$ Frequencies

The relationship among monthly averaged temperature, relative humidity and water vapour pressure characteristics are plotted. The amplitude scintillations are directly proportional to the wet term radio refractivity and the wet term refractivity directly proportional to the temperature and inversely proportional to the relative humidity. Monthly averaged relative humidity is directly proportional to the height and temperature inversely proportional of the turbulent layer from earth's surface.

Relative humidity is Inversely proportional to the temperature. The measured fades stretch up to $.00115 \mathrm{~dB}$ and $0.00094 \mathrm{~dB}$ at $0.01 \%$ of time at $30.5 \mathrm{GHz}, 20.2 \mathrm{GHz}$ of frequencies and $1000 \mathrm{~m}$ of turbulent layers height. Signal stretched to $0.01055 \mathrm{~dB}$ from $20.2 \mathrm{GHz}$ to $30.5 \mathrm{GHz}$ and the standard error is $1.47952 \mathrm{~dB}$ in scintillation and $3.5813 \mathrm{~dB}$ in radio refractivity.

Refractive index is 1.00005283. the variation in refractive index is 0.00005283 from standard refractive index.

\section{CONCLUSION}

Measured data analyzed and estimated on tropospheric scintillations on ka band satellite signals for Indian climate which is used in adaptive link control in the design of satellite communication system. The new prediction of scintillations observed by using Gaussian distribution and third order polynomial fit to the measured values of India's tropical climate. The standard deviation is increased with the increased frequency and decreased elevation angle, is proven with simulation. Statistics were estimated at different attenuated levels, higher values in ka band. because scintillations effect very strong with high frequency. Small signals wavelength leads more fluactions. The $\mathrm{Ka}$ band signal communication link affected strongly by phenomenon of scintillations.

\section{REFERENCES}

1. Satellite communications, Thimothy pratt , Charless W.Bostian, Jeremy E.Allnutt $2^{\text {nd }}$ ed.2007.

2. "ITUR P618-12 "Prediction methods and Propagation data required for the design of earth space telecommunication System, Ed.2012.

3. "ITUR P.453-10"' Refractivity data, formula and radio refractive index.ed.2012.

4. http:/weather.uwyo.edu. 


\section{BAND FREQUENCIES}

5. Climatic Radiowave Propagation Models for the design of Satellite Communication Systems , M.M.J.L. van de Kamp Eindhoven, 24 november 1999.

6. J.E.Allnut, M.Yamuda, Karasawa.Y.”A New Prediction Method for Tropospheric Scintillation on Earth Space Paths"Propagation and Antenaas, IEEE Transactions on Vol.36, PP.1608-1614, 1988.

7. Aeronatics.USN, T \&Space.SAO, Propagation Effects Handbook, Applications for Satellite system design on 10100GHz Satellite link, 1980.

8. "EdusatUtilization Program, Dept. of space, 2013.

9. http://nasa.gov.com.

10. Gsat4 satellite details, 2013.

11. HTTP://www.researchgate.net.

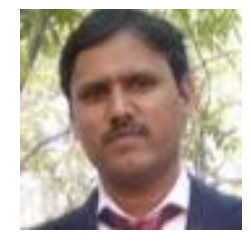

Auther1:Research scholar in the area of Satellite Communications, In Dept. of ECE, from Gitam University, Visakhapatnam, A.P.India.M.Tech in Digital Electronics and Communication Systems in ECE from MIST, , JNTU Hyderabad.TS, India.B.Tech.in ECE, from JITS, Warangal, TS, India. Asset mapping Project Coordinator from MIST toIETE/NRSC/ISRO/2017.Membership:M500332,

MISTE:LM:64543.International Publications including Scopus indexed, IEEE Explorer, IETE etc:conferences:9 Journals :6. 